\title{
SH (Australia) Antigen in Early Life
}

\author{
G. C. TURNER, ANNE M. FIELD, RAGAA M. LASHEEN, R. MCL. TODD, \\ G. B. B. WHITE, and A. A. PORTER \\ From the Regional Public Health Laboratory, Liverpool, Central Public Health Laboratory, Colindale, and Department \\ of Child Health, University of Liverpool
}

\begin{abstract}
Turner, G. C., Field, A. M., Lasheen, R. M., Todd, R. McL., White, G. B. B., and Porter, A. A. (1971). Archives of Disease in Childhood, 46, 616. SH (Australia) antigen in early life. A woman in the antigenaemic phase of acute hepatitis gave birth to a female child after 35 weeks' gestation. No antigen was detected in the child's blood at birth or after 32 days. At 59 days, however, the test for antigen was strongly positive. The child remained well with no jaundice or other clinical evidence of disease, but positive tests for antigen and raised serum alanine transferase levels persisted throughout the first 2 years of life. Evidence from serological tests and electron microscopical appearances suggested that the infant developed some antibody but not sufficient to eliminate the antigen. The significance of these findings is discussed in relation to long-term carriage of serum hepatitis virus by healthy subjects, and the possibility of 'vertical transmission' from mother to child.
\end{abstract}

A specific antigen described variously as $\mathrm{SH}$ antigen (Prince, 1968), Australia antigen (Blumberg et al., 1967), hepatitis antigen (Gocke and Kavey, 1969), and hepatitis-associated antigen (McCollum, 1969) can be detected in the blood of patients late in the incubation period and in the acute phase of serum hepatitis. It has been found too, in the blood of healthy persons who have been incriminated on epidemiological grounds as carriers of serum hepatitis virus. In such cases a history is often lacking, and the genesis of this 'silent' carrier state has been the subject of much speculation.

We report here the transmission of $\mathrm{SH}$ antigen from a mother to her infant. The child was born during the antigenaemic phase of maternal hepatitis and developed positive tests for antigen and raised serum alanine aminotransferase values after an interval corresponding to the incubation period of serum bepatitis. Other abnormalities were not detected and the child developed normally. At 2 years of age tests for $\mathrm{SH}$ antigen were still positive and though alanine transferase levels had declined they were still above the normal range. Serial specimens of serum were obtained from this child during the first 2 years of life and these were examined for the presence of antigen by serological methods and by electron microscopy.

\footnotetext{
Received 5 April 1971.
}

The child's father developed antigen-positive hepatitis 2 months before his wife, and antigen was detected in the serum of a medical laboratory technician who developed the disease after undertaking biochemical tests on the child's serum.

\section{Methods}

Serological tests. All serum specimens were tested for antigen by 3 serological methods: immunodiffusion (Prince, 1968), cross-over electrophoresis, and complement fixation (White et al., 1971).

Electron microscopy. For direct examination, 0.2 $\mathrm{ml}$ serum was diluted to $2.5 \mathrm{ml}$ with phosphate-buffered saline and centrifuged at 18,000 r.p.m. in the SS-34 rotor of a Sorvall RC2-B centrifuge. The pellet was then resuspended in approximately $0.05 \mathrm{ml}$ distilled water. The suspension was mixed with an equal volume of $3 \%$ potassium phosphotungstate negative stain at $p H 6 \cdot 0$, a drop applied to a formvar-carboncoated type 400 specimen grid, and the excess removed by blotting with filter paper. Grids were examined in an AEI EM6B electron microscope at a magnification of 60,000 .

For serum containing few particles the technique of immune electron microscopy was used to aggregate the particles. $0.1 \mathrm{ml}$ serum containing antibody was added to $0.2 \mathrm{ml}$ serum under test and the mixture incubated for 30 minutes at room temperature; it was then diluted, centrifuged, and negatively-stained as above. 


\section{Results}

Parents. The husband, aged 21 years, developed hepatitis at the end of June 1969 after an injection with an unsterile syringe in the preceding April. On admission to hospital on 22 July his serum bilirubin was $15.3 \mathrm{mg} / 100 \mathrm{ml}$ and his alanine transferase level was 425 units $/ 100 \mathrm{ml}$. He recovered uneventfully. Immunodiffusion tests for $\mathrm{SH}$ antigen gave negative results with serum samples collected on 28 July and 4 and 11 August, but all were positive when tested by the cross-over electrophoresis technique. The second and third samples were tested by complement fixation; the second was positive at a dilution of 1 in 4 and the third was negative.

The wife, aged 21 years, became jaundiced on 7 September. Her baby was born the following day when her levels of serum bilirubin and alanine transferase were $6.0 \mathrm{mg} / 100 \mathrm{ml}$, and 440 units/100 $\mathrm{ml}$ respectively, and when tests for antigen were strongly positive (Table I). Her recovery was uneventful and by 25 September tests for antigen gave much weaker results when measured by complement fixation. At that time serum bilirubin and alanine transferase levels were $1.3 \mathrm{mg} / 100 \mathrm{ml}$, and 190 units $/ 100 \mathrm{ml}$. Additional tests were not done for nearly a year by which time antigen test results were negative and alanine transferase values were within normal limits. Marked alterations in levels of immunoglobulins $\mathbf{M}, \mathbf{A}$, and $\mathbf{G}$ were not detected; this is not an uncommon finding in acute hepatitis (Peters and Ashcavai, 1970).

Child. The female infant was born at 35 weeks' gestation and weighed $2070 \mathrm{~g}$. Her length was $46 \mathrm{~cm}$, head circumference $30 \mathrm{~cm}$, and tests on cord blood gave the following results: blood group O $\mathrm{Rh}$ positive, haemoglobin $16 \cdot 1 \mathrm{~g} / 100 \mathrm{ml}$, Coombs test negative. Clinical examination at birth showed no abnormality apart from the usual features of immaturity. Respiratory distress syndrome developed 90 minutes after delivery and $8 \cdot 4 \%$ sodium bicarbonate was given, intravenously at first and then orally with each three-hour feed. The baby was not breast-fed. 4 days later she was clinically normal but her serum calcium level was only $6.5 \mathrm{mg} / 100 \mathrm{ml}$; after oral calcium gluconate it rose to $9 \cdot 2 \mathrm{mg} / 100 \mathrm{ml}$ by the 8 th day of life.

Physiological jaundice developed on the 3rd day, and though the serum bilirubin value reached $12.5 \mathrm{mg} / 100 \mathrm{ml}$ (indirect $11.5 \mathrm{mg} / 100 \mathrm{ml}$ ) by the 7 th day, it then declined and jaundice was not observed clinically after the 11th day. Subsequent progress and development were satisfactory.

At birth SH antigen was not detected in the child's blood, urine, or faeces; cord blood was also negative. Blood samples collected 15 and 32 days after birth were negative and both alanine transferase and immunoglobulin values were within normal limits (Table II)

The test for SH antigen had become strongly positive by the 59th day after birth though alanine transferase and immunoglobulin levels had not changed significantly. At 80 days, however, the antigen test was still strongly positive, the transferase value was very high, and there was some increase in immunoglobulin $M$. Similar findings were obtained 2 weeks later, but thereafter the IgM level was within normal limits.

During the next few months alanine transferase levels fluctuated but remained high and tests for antigen remained strongly positive. Some weakening of the reaction for antigen was apparent however by the 22nd week and this was more marked by 45 weeks. The change was accompanied by a slow decline in alanine transferase levels and by first a sustained rise in the level of $\mathrm{IgG}$, with later a secondary increase in IgM.

When the child was nearly 2 years old, the test for antigen was still positive at a dilution of $1 / 64$

TABLE I

Results of Biochemical Investigations and Tests for Antigen in Mother after Onset of Hepatitis

\begin{tabular}{|c|c|c|c|c|c|c|c|}
\hline \multirow{2}{*}{$\begin{array}{l}\text { Days After } \\
\text { Onset of } \\
\text { Hepatitis }\end{array}$} & \multirow{2}{*}{$\begin{array}{c}\text { Serum } \\
\text { Bilirubin } \\
(\mathrm{mg} / 100 \mathrm{ml})\end{array}$} & \multirow{2}{*}{$\begin{array}{c}\text { Serum Alanine } \\
\text { Amino- } \\
\text { transferase } \\
(\mathrm{U} / 100 \mathrm{ml})\end{array}$} & \multicolumn{3}{|c|}{ Immunoglobulins $(\mathrm{mg} / 100 \mathrm{ml})$} & \multicolumn{2}{|c|}{ Tests for Antigen } \\
\hline & & & $\mathbf{M}$ & A & G & COE & CFT \\
\hline $\begin{array}{l}1 \\
5 \\
12 \\
15 \\
18 \\
46 \text { (wk) }\end{array}$ & $\begin{array}{l}6 \cdot 0 \\
8 \cdot 3 \\
\text { NT } \\
3 \cdot 1 \\
1 \cdot 3 \\
\text { NT }\end{array}$ & $\begin{array}{r}440 \\
410 \\
\text { NT } \\
115 \\
190 \\
30\end{array}$ & $\begin{array}{l}\text { NT } \\
70 \\
57 \\
\text { NT } \\
43 \\
\text { NT }\end{array}$ & $\begin{array}{l}\text { NT } \\
315 \\
230 \\
\text { NT } \\
230 \\
\text { NT }\end{array}$ & $\begin{array}{l}\text { NT } \\
1040 \\
1200 \\
\text { NT } \\
1125 \\
\text { NT }\end{array}$ & $\begin{array}{l}+ \\
+ \\
+ \\
+ \\
+ \\
-\end{array}$ & $\begin{array}{r}128 \\
32 \\
16 \\
8 \\
8 \\
<2\end{array}$ \\
\hline
\end{tabular}

$\mathrm{COE}=$ cross-over electrophoresis $; \mathrm{CFT}=$ complement-fixation titre; $\mathrm{NT}=$ not tested. 
TABLE II

Results of Biochemical Investigations and Tests for Antigen on Child During First 2 Years of Life

\begin{tabular}{|c|c|c|c|c|c|c|c|}
\hline \multirow{2}{*}{$\begin{array}{l}\text { Days or } \\
\text { Weeks } \\
\text { After Birth }\end{array}$} & \multirow{2}{*}{$\begin{array}{c}\text { Serum Alanine } \\
\text { Aminotransferase } \\
(\mathrm{U} / 100 \mathrm{ml})\end{array}$} & \multicolumn{3}{|c|}{ Immunoglobulins (mg/100 $\mathrm{ml}$ ) (and normal ranges) } & \multicolumn{3}{|c|}{ Tests for Antigen } \\
\hline & & $\mathbf{M}$ & $\mathbf{A}$ & $\mathbf{G}$ & COE & CFT & $\mathbf{E M}$ \\
\hline
\end{tabular}

$\mathrm{COE}=$ cross-over electrophoresis. $\quad \mathrm{CFT}=$ complement-fixation titre. $\quad \mathrm{AC}=$ anticomplementary. $\mathrm{EM}=$ electron microscopy. $\mathbf{F}=$ free antigen only, not aggregated. $\quad F, A=$ free and aggregated antigen present. NT $=$ not tested.

by complement fixation but the IgM level had declined to normal limits and the alanine transferase value (125 units $/ 100 \mathrm{ml}$ ) was at the lowest level encountered since an abnormality was first detected.

Throughout the investigation the child has remained clinically well; despite the high levels of alanine transferase detected, there has not been hepatomegaly or any other clinical evidence of liver damage. A liver biopsy has not been performed.

Medical laboratory technician. During the investigation a positive test for $\mathrm{SH}$ antigen (CFT 1/64) was obtained with a serum sample collected 12 days after the onset of hepatitis in a female senior technician who had been undertaking biochemical tests on serum samples from the child. 6 weeks later tests on the technician's serum gave negative results and her serum bilirubin level had fallen from $13 \mathrm{mg} / 100 \mathrm{ml}$ to normal. Serum alanine transferase levels remained high for several weeks before declining to physiological levels.

\section{Electron Microscopy}

Mother. Appearances typical of acute antigenpositive hepatitis were demonstrated by electron miscroscopy in serum samples collected from the mother 1, 5, 12, and 15 days after parturition; small round particles about $22 \mathrm{~nm}$ in diameter and long forms about $22 \mathrm{~nm}$ wide and varying lengths were seen (Fig. 1). It was necessary to use immune electron microscopy to detect antigen in the sera taken 12 and 15 days after parturition but antigen was readily visible in the first two serum samples without the use of detector serum.

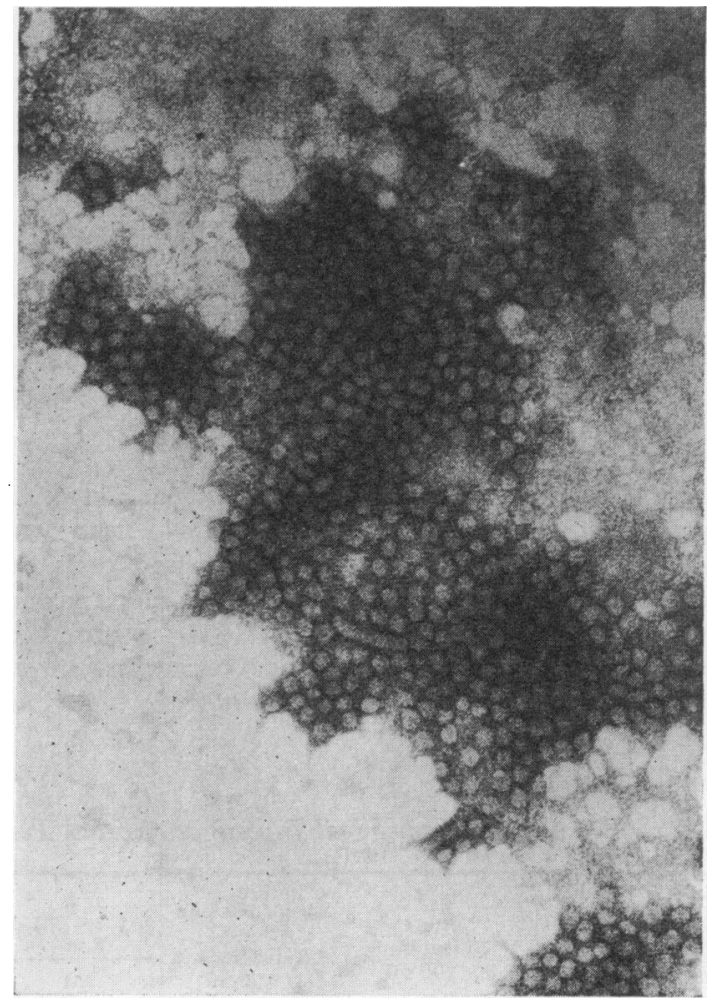

FIG. 1.-Antigen detected by immune electron microscopy in the mother's serum 5 days after parturition. ( $X$ 90,000.)

The sample taken 18 days after parturition was examined without the use of antiserum and no antigen was detected. 


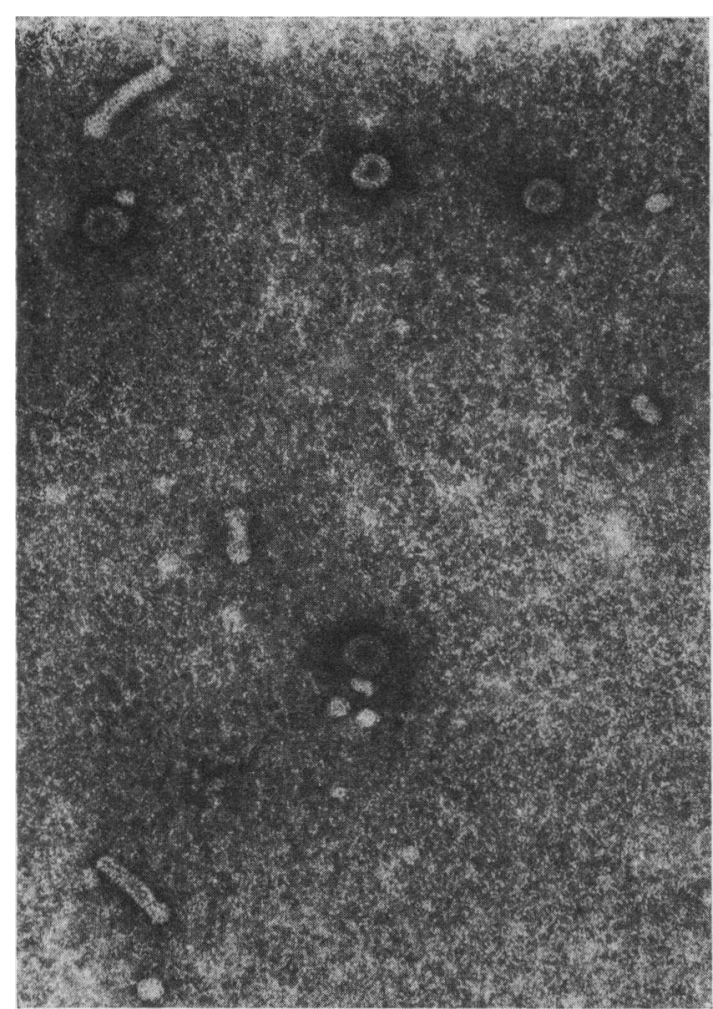

FIG. 2.-Three forms of antigen in the child's serum 80 days after birth. $(\times 90,000$.

Child. Three types of particle were observed in serum samples collected from the child 59, 80, and 94 days after birth (Fig. 2). Small $22 \mathrm{~nm}$ diameter round particles, and a very large number of long forms were present. Numerous larger (40$42 \mathrm{~nm}$ ) double-shelled particles similar to those described by Dane, Cameron, and Briggs (1970) were also seen.

At this stage in the investigation and at 22 and 24 weeks from birth when the small round antigen particles were more numerous than in earlier sera (Fig. 3) aggregation of particles was not seen. At 28 and 36 weeks, however, some clumping was evident, which involved each of the 3 types of particles (Fig. 4). At 45 weeks when definite weakening of the positive serological test for antigen was detected (Table II) quite large aggregates were seen; a striking feature of these was the high proportion of long forms present. There were also numerous free particles. Wright et al. (1970) described similar very long forms in the serum of an infant who developed acute hepatitis at 19 weeks.
Laboratory technician. The serum sample collected 12 days after onset contained a mixture of free and aggregated antigen particles. Some aggregates were very large (Fig. 5). Small $22 \mathrm{~nm}$ diameter round particles, long forms, and a few double-shelled particles were seen.

\section{Discussion}

The child described here was born when its mother's serum was strongly positive in tests for SH (Australia) antigen. At birth, however, antigen was not detectable in the infant's blood, nor in the cord blood: these findings were in agreement with those of London, DiFiglia and Rodgers (1969), Hawkes (1970), and Smithwick and Go (1970), who were unable to demonstrate transplacental transmission of antigen.

Tests for antigen on the child's serum were negative during the first 32 days after birth, but at 59 days were strongly positive. This was the only abnormality detected at that time, but 21 days later in addition to a positive test for antigen, a high alanine transferase level was noted and also a

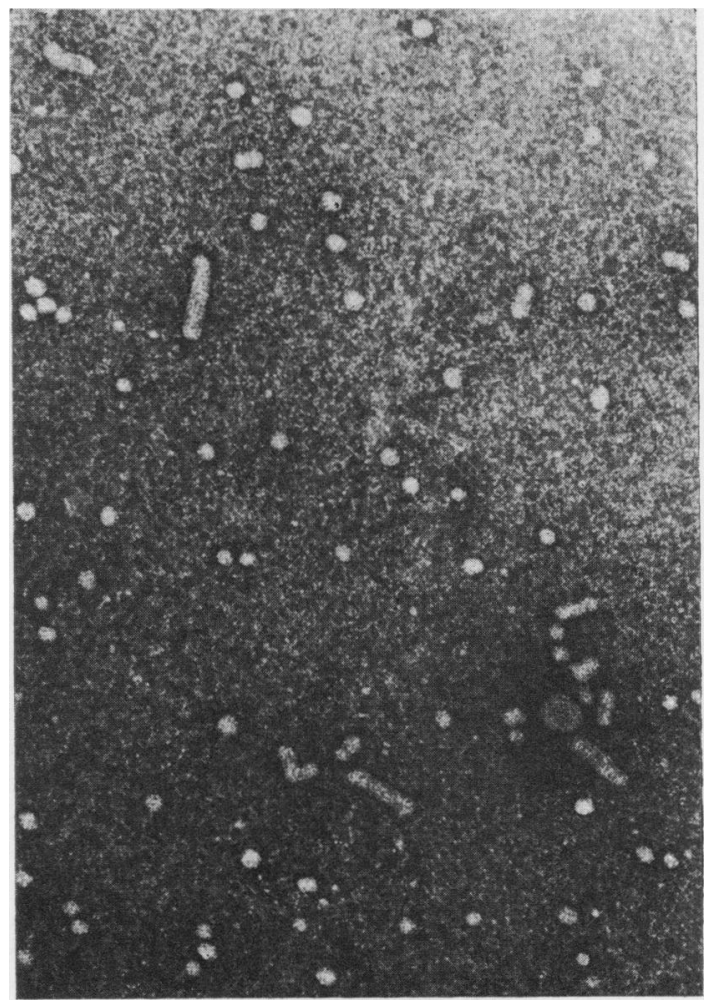

FIG. 3.-Numerous small (22 $\mathrm{nm}$ ) round forms of antigen in the child's serum 24 weeks after birth. ( $\times$ 90,000.) 


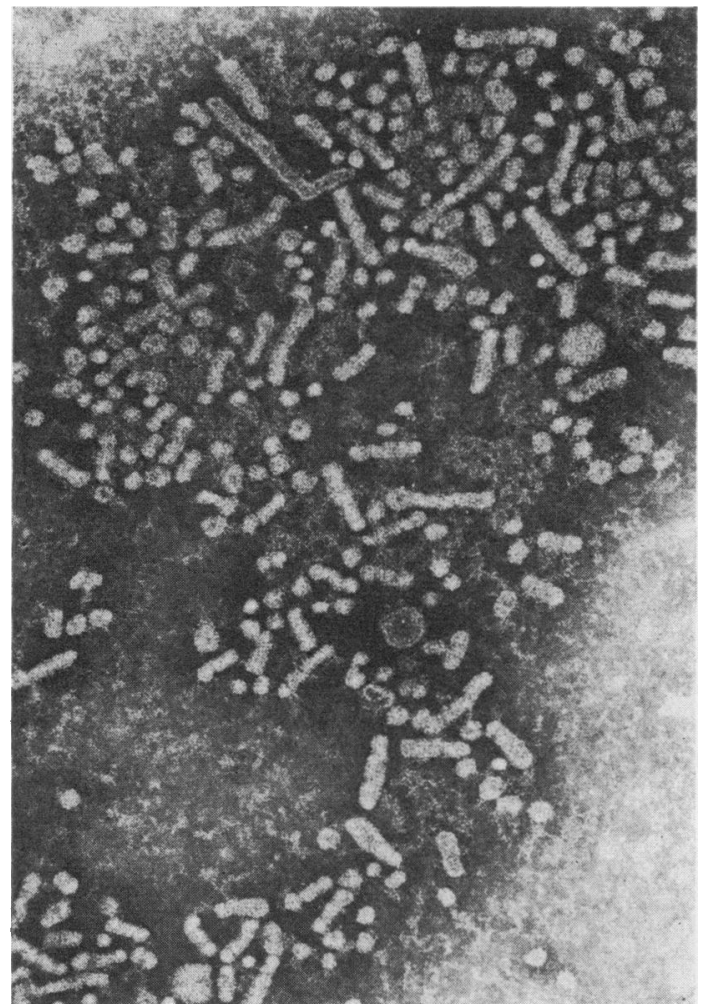

FIG. 4.-Agglutinated and some free antigen in the child's serum 45 weeks after birth. $(\times 90,000$.

sharp increase in IgM. These findings were consistent with the transmission of infection from mother to child at parturition and the development of an anicteric hepatitis after an interval corresponding to the incubation period of serum hepatitis. The appearance of antigen in the child's serum before a biochemical abnormality was detected parallels the experience of Prince (1968) in his study of an adult case.

The subsequent history of this premature baby is of great interest in view of the exceptionally early exposure to infection. In fact, the child remained clinically well despite a persistent increase in alanine transferase levels. It is unlikely that biochemical tests would have been considered in this apparently normal infant but for the continued surveillance instituted after the demonstration of antigen at 59 days.

Tests for antigen were still positive when the child was nearly 2 years old. Indeed tests remained strongly positive for more than 6 months in contrast to our findings in the mother in whom positive serological reactions began to weaken soon after the onset of her illness (Table I). Strongly positive serological tests in the child correlated with electron microscopy findings that antigen particles were in the free state; no aggregates were seen in the early sera. At 45 weeks some weakening of the positive serological reaction was detected and this was associated with the appearance of antigen aggregates in the child's serum. These findings are compatible with the view that serological tests detect 'free' antigen, i.e. antigen that has not been bound in the aggregates (antigen-antibody complexes) seen by electron microscopy (Cossart et al., 1971).

In this child, in contrast to the usual findings in an adult patient, the serological and electron miscroscopical findings suggested such a slow development of the immunological response that at 2 years it was still ineffective in the elimination of antigen: at that time tests for antigen were still positive though their strength had declined to a fairly constant level. It is perhaps worthy of note that two transient increases were observed in the

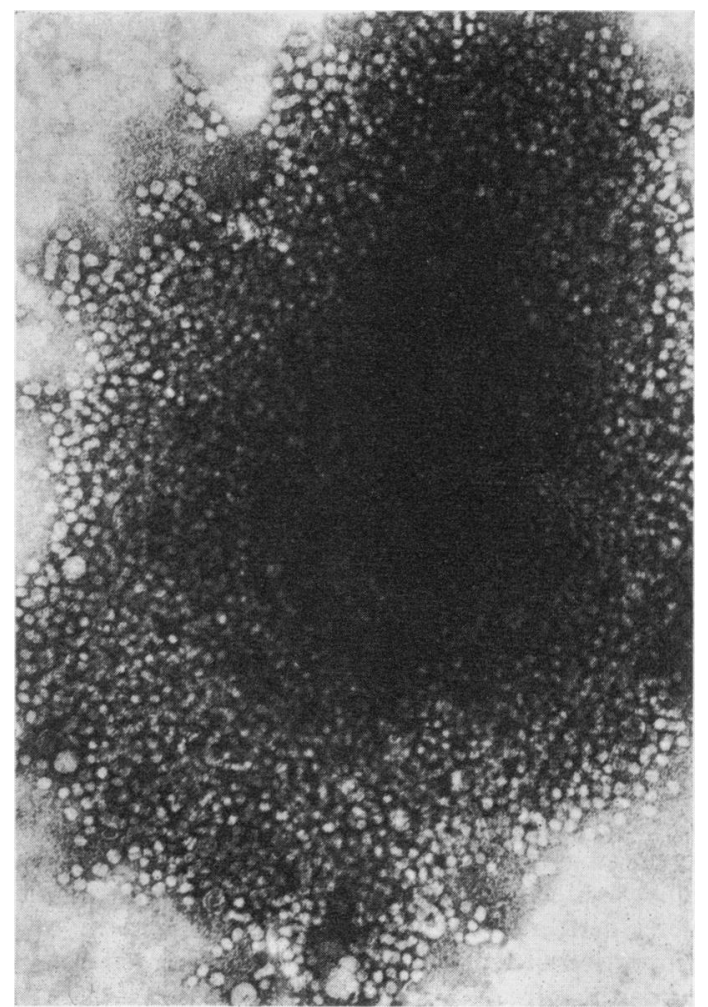

Fig. 5.-Very large clump of agglutinated antigen in the laboratory technician's serum 12 days after onset. $\times 60,000$.) 
levels of $\operatorname{IgM}$ in the absence of any clinical illness. The first coincided with the initial increase in serum alanine transferase values following the appearance of SH antigen; the second corresponded in time with a weakening of antigen titre as shown by the serological tests.

Schweitzer and Spears (1970) have reported 3 infants in whom antigen was detected after their mothers developed antigen-positive hepatitis while pregnant or shortly after delivery. In 2 of these cases parturition occurred during the incubation period of the disease, but the infants themselves were not tested for antigen until they were 47 and 85 days old, respectively. In the third case the child was delivered after the onset of maternal hepatitis but at a time when the mother's blood was still antigen-positive; at birth antigen was not detected in this baby's serum but was found to be present 7 weeks later. One of the 3 children was studied for $2 \frac{1}{2}$ months and another for 6 months after the first positive test for antigen. In each, the test remained positive in the absence of clinical illness though there were persistently raised serum aspartate and alanine transferase levels in one. Schweitzer and Spears also reported the case of another mother who was antigen-positive at parturition and who gave birth to an antigennegative baby; later developments were not recorded.

Gillespie et al. (1970) have described a case in which SH antigen was detected in the serum of a 4-month-old male infant admitted to hospital for treatment of pneumonia. Biochemical tests suggested the presence of a concomitant and presumably unsuspected neonatal hepatitis which was confirmed by liver biopsy. The mother, too, was found to be antigen-positive, and it is of some interest that she appeared to be a symptom-free carrier lacking any history of jaundice, hepatitis, or blood transfusion. Wright et al. (1970) reported a similar case of a female infant who, when 19 weeks old, developed acute hepatitis which subsequently became chronic with active cirrhosis at 1 year; positive tests for antigen were obtained with serum specimens from both the infant and from the mother who had had jaundice at the end of her pregnancy.

Before the availability of tests for SH antigen there had been several reports of hepatitis in the early months of life. Williams and Gaber (1949) reported fatal hepatitis in a child of 8 weeks. Scott, Wilkins, and Kessler (1954) described a family in which 3 sibs died from hepatitis developing 4 weeks, 1 week, and 4 months after birth respectively: liver function tests gave abnormal results in the mother and 2 other sibs. Stokes et al. (1954) investigated a child, not breast-fed, who became jaundiced 2 months after delivery by caesarean section. When the child was 9 months old, 3 of 5 volunteers developed hepatitis after an injection of the mother's blood and 2 of 5 volunteers were similarly affected after receiving blood from the infant. The child itself developed fibrosis of the liver and died when 18 months old. Beard (1956) described the case of a woman whose serum gave an abnormal result in a cephalin flocculation test; her first and second children developed

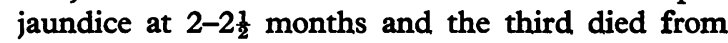
hepatitis at 76 days. In those instances where several sibs developed hepatitis, chronic carriage of the causative agent by the mother is clearly a possibility. In most of these reported cases the interval between the birth of the child and the onset of its illness was consistent with infection at parturition with the agent of long incubation hepatitis.

Our findings in the case reported here and those of Schweitzer and Spears and Gillespie et al. show that antigen-associated infection transmitted from mother to infant may be without any apparent ill effects or may cause only minimal liver damage, not revealed by clinical examination. There are however, earlier reports of frank, sometimes fatal hepatitis in infants in whom the underlying cause may have been the same though this cannot be proved. Detection and careful long-term study of similar cases is clearly required.

The importance of antigen-associated infection in early life lies not only in its causal relation to liver disease but also in its possible significance in the genesis of long-continued carriage of serum hepatitis virus. The child reported here was still antigen positive more than 22 months after its first positive test at 8 weeks of age; the 2 children studied by Schweitzer and Spears for $2 \frac{1}{2}$ and 6 months respectively were still antigen positive when their cases were reported. The carrier state may be life-long; Zuckerman and Taylor (1969) have described an instance of carriage for 20 years. In the light of these facts we suggest that female infants carrying virus as a result of infection at birth may later transmit it to their own offspring in the child-bearing years. Such a sequence of events would represent the 'vertical' transmission of hepatitis virus postulated to explain the carriage of the agent by donors lacking either a history of the disease or of blood transfusion. If infection of infants can occur at parturition, the necessity for invoking transplacental transmission in explanation does not arise. An important factor in such a 
cycle of transmission must be the peculiar host response in the baby as a result of which hepatocellular damage may be minimal and elimination of antigen incomplete. These two factors are almost certainly interrelated; Almeida and Waterson (1969) suggested that the clinical severity of hepatitis depended upon the extent of the antibody response.

Blumberg et al. (1966) found evidence of familial clustering of carriers of Australia antigen and sought an explanation in terms of genetic susceptibility. It may be, however, that the explanation lies in mother-to-child transmission of an infective agent.

Support for this concept comes from the findings of Ohbayashi, Mayumi, and Okochi (1971) who described 2 families in which there was a high incidence of familial cirrhosis and positive tests for Australia antigen. In the 2 families there were 10 surviving male and female sibs and all were antigenpositive; of the 13 children of the female sibs, 12 were antigen-positive but all 4 children of the male sibs were antigen-negative.

We thank Dr. D. A. Stanley, Dr. T. H. Williets, and Miss M. P. McLaughlin of Royal Liverpool Children's Hospital, and Dr. P. O. Jones and Miss O. F. Dinsdale of Sefton General Hospital, Liverpool, for their help in the investigation of this family.

Dr. R. M. Lasheen was on leave of absence from her post of Lecturer in Bacteriology, Ain Shams University, Cairo.

\section{REFERENCES}

Almeida, J. D., and Waterson, A. P. (1969). Immune complexes in hepatitis. Lancet, 2, 983.

Beard, A. G. (1956). Hepatitis in three siblings. Fournal of Pediatrics, 49, 454.

Blumberg, B. S., Gerstley, B. J. S., Hungerford, D. A., London, W. T., and Sutnick, A. I. (1967). A serum antigen (Australia antigen) in Down's syndrome, leukemia, and hepatitis. Annals of Internal Medicine, 66, 924

Blumberg, B. S., Melartin, L., Guinto, R. A., and Werner, B. (1966). Family studies of a human serum isoantigen system (Australia antigen). American fournal of Human Genetics, 18, 594.

Cossart, Y. E., Field, A. M., Hargreaves, F. D., and Porter, A. A. (1971). Morphology and immunological properties of Australia/SH antigen in hepatitis. Microbios, 3,5 .

Dane, D. S., Cameron, C. H., and Briggs, M. (1970). Virus-like particles in serum of patients with Australia-antigen-associated hepatitis. Lancet, 1, 695.
Gillespie, A., Dorman, D., Walker-Smith, J. A., and Yu, J. S. (1970). Neonatal hepatitis and Australia antigen. Lancet, 2,1081 .

Gocke, D. J., and Kavey, N. B. (1969). Hepatitis antigen: correlation with disease and infectivity of blood-donors. Lancet, 1 , 1055.

Hawkes, R. A. (1970). Australia antigen and viral hepatitis in Sydney; a hospital series. Medical fournal of Australia, 2, 519.

London, W. T., DiFiglia, M., and Rodgers, J. (1969). Failure of transplacental transmission of Australia antigen. Lancet, 2, 900.

McCollum, R. W. (1969). Serum antigens in viral hepatitis. fournal of Infectious Diseases, 120, 641.

Ohbayashi, A., Mayumi, M., and Okochi, K. (1971). Australia antigen in familial cirrhosis. Lancet, 1, 244.

Peters, R. L., and Ashcavai, M. (1970). Immunoglobulin levels in detection of viral hepatitis. American fournal of Clinical Pathology, 54, 102.

Prince, A. M. (1968). An antigen detected in the blood during the incubation period of serum hepatitis. Proceedings of the National Academy of Sciences of the United States of America, $60,814$.

Schweitzer, I. L., and Spears, R. L. (1970). Hepatitis-associated antigen (Australia antigen) in mother and infant. New England Fournal of Mcdicine, 283, 570.

Scott, R. B., Wilkins, W., and Kessler, A. (1954). Viral hepatitis in early infancy. Report of three fatal cases on siblings simulating biliary atresia. Pediatrics, 13, 447.

Smithwick, E. M., and Go, S. C. (1970). Hepatitis-associated antigen in cord and maternal sera. Lancet, 2, 1080.

Stokes, J., Jr., Berk, J. E., Malamut, L. L., Drake, M. E., Barondess, J. A., Bashe, W. J., Wolman, I. J., Farquhar, J. D., Bevan, B., Drummond, R. J., Maycock, W. D'A., Capps, R. B., and Bennett, A. M. (1954). The carrier state in viral hepatitis. fournal of the American Medical Association, 154, 1059.

White, G. B. B., Lasheen, R. M., Baillie, M. B., and Turner, G. C. (1971). Comparison of three serological methods for the detection of hepatitis-associated antigen. Fournal of Clinical Pathology, 24, 8.

Williams, R. R., and Gaber, B. (1949). The fulminant form of epidemic hepatitis in a two-month-old infant. Fournal of Pediatrics, 35, 244.

Wright, R., Perkins, J. R., Bower, B. D., and Jerrome, D. W. (1970). Cirrhosis associated with the Australia antigen in an infant who acquired hepatitis from her mother. British Medical fournal, 4, 719.

Zuckerman, A. J., and Taylor, P. E. (1969). Persistence of the serum hepatitis (SH-Australia) antigen for many years. Naiure (London), 223, 81.

\section{Addendum}

Since this paper was written we have detected antigen in another infant, a patient of Dr. A. C. Kirby. This male child was born to a woman in the antigenaemic phase of acute hepatitis. The child's blood was antigennegative at 55 days but strongly positive at 83 days; clinical examination, however, revealed no abnormality.

Correspondence to Dr. G. C. Turner, Public Health Laboratory, 126 Mount Pleasant, Liverpool L3 5SU. 